\title{
O DIREITO À AGUA FRENTE A AUSÊNCIA DE INFORMAÇÃO SOBRE O SURTO DE TOXOPLASMOSE NOS ANOS 2017-2018 EM SANTA MARIA-RS
}

\section{Dion Roger Chavier Ribeiro'; Francielle Benini Agne Tybusch²}

\section{RESUMO}

O presente trabalho teve como objetivo estudar sobre o direito à água no caso do surto de toxoplasmose nos anos 2017-2018, em uma análise das consequências da doença na população de Santa Maria- RS. Assim, a pesquisa teve como problema compreender quais os limites e possibilidades para assegurar o direito à agua na cidade de Santa Maria/RS frente à ausência de informação sobre o surto de toxoplasmose, nos anos 2017-2018 em Santa Maria - RS. Para responder esta questão, utilizou-se do o método de abordagem indutiva; como método de procedimento foi utilizado o método monográfico; e como técnicas de pesquisa foram utilizadas documentações indiretas de livros, revistas jurídicas e artigos científicos. Assim, verificou-se que o direito à agua e o acesso à informação são de suma importância para que a população e as equipes de saúde possam agir diante de surtos como o ocorrido em Santa Maria - RS.

Palavras-chave: Direito à água; Informação; Surto de toxoplasmose; Santa Maria.

Eixo Temático: Direitos, Políticas Públicas e Diversidade (DPD)

\section{INTRODUÇÃO}

O presente trabalho tem como objetivo estudar sobre o direito a água no caso do surto de toxoplasmose nos anos 2017-2018 em Santa Maria - RS, em uma

\footnotetext{
${ }^{1}$ Mestrando no Programa de Pós-Graduação Mestrado Acadêmico em Ensino de Humanidades e Linguagens- UFN. Graduado em Direito pela Universidade Franciscana - UFN. E-mail: dion.ribeiro@ufn.edu.br

${ }^{2}$ Doutora em Direito pela Unisinos. Mestre em Direito pela UFSM. Docente do Curso de Direito da UFN. E-mail: francielle agne@gmail.com
} 
análise das consequências da doença na população de Santa Maria- RS. Assim, tem como problema de pesquisa compreender quais os limites e possibilidades para assegurar o direito à agua na cidade de Santa Maria/RS frente a ausência de informação sobre o surto de toxoplasmose, nos anos 2017-2018 em Santa Maria RS? Quais as consequências da doença na população neste período?

Assim, este trabalho se destaca cientificamente pois a temática do acesso à água potável e limpa é uma questão essencial e indispensável para a subsistência da vida humana e para o funcionamento do ecossistema da terra. O problema do acesso a água ainda é crucial para muitos (as) na atual sociedade.

A água é um direito fundamental e universal sendo previsto constitucionalmente no ordenamento brasileiro, com base de grande relevância ao direito e proteção ao meio ambiente onde expressamente diz: "Todos têm direito ao meio ambiente ecologicamente equilibrado, bem de uso comum do povo e essencial à sadia qualidade de vida, impondo-se ao Poder Público e à coletividade o dever de defendê-lo e preservá-lo para as presentes e futuras gerações" (BRASIL, 1988).

Este trabalho tem como justificativa social ser de grande importância pois atingiu um grande número de pessoas, sendo considerado um dos maiores surtos de toxoplasmose do mundo (BBC, 2017). De acordo com os documentos divulgados pelos órgãos da saúde (UFSM, 2018), o município de Santa Maria possuía 1.116 casos notificados. Isso quer dizer que essa quantidade de pessoas apresentou os sintomas de síndrome febril (febre, dor de cabeça e no corpo, falta de apetite e aparecimento de ínguas na cabeça e no pescoço). Ainda, 140 casos que foram descartados para a doença, entre eles um aborto e 32 casos de gestantes, 166 seguem em investigação em Santa Maria/RS. Por fim, este trabalho se justificativa pessoalmente por ser uma temática que despertou o interesse durante a faculdade, e após o fato, visto a falta de acesso a informação para a sociedade.

\subsection{O DIREITO AO ACESSO À INFORMAÇÃO SOBRE A ÁGUA NO CASO DO SURTO DE TOXOPLASMOSE}


A água, como mencionado no item anterior, ocupa cerca de $70 \%$ da superfície terrestre trazendo uma ideia falsa da inesgotabilidade desse recurso. Quando se visualiza o globo, principalmente esse azul que encanta, na verdade somente $3 \%$ de toda a agua é doce (UN WATER, 2021).

Importante definição é a de água potável adotada pela Portaria № 2.914 , de 12 de dezembro de 2011, artigo $5^{\circ}$, II, que "água que atenda ao padrão de potabilidade estabelecido nesta Portaria e que não ofereça riscos à saúde. Para João Hélio (2019, p. 07) "é aquela que reúne as características necessárias para ser consumida sem importar qualquer risco à saúde e ao bem-estar dos seres humanos".

O corpo humano é formado por $55 \%$ a $78 \%$ de água de composição isso dependendo da massa corporal e, apenas a perda de 15\% nos leva a óbito, isto reflete a importância do ar e da agua como fundamentais para a sobrevivência humana (BARLOW; CLARKE, 2003). A regulamentação da água na esfera jurídica, vem sido atualizada regularmente, devido a sinalização de sua escassez, cada vez mais presente no mundo.

A Organização Mundial nas Nações Unidas publicou previsões em seu último Relatório Mundial das Nações Unidas sobre Desenvolvimento dos Recursos Hídricos 2021, "estresse hídrico, mensurado essencialmente pelo uso da água em função do suprimento disponível, afeta diversas partes do mundo. Mais de 2 bilhões de pessoas em todo o mundo vivem em países em situação de estresse hídrico" (UN WATER, 2021).

De acordo com o mesmo relatório "Cerca de 1,6 bilhão de pessoas enfrentam escassez "econômica" de água, o que significa que, embora a água possa estar fisicamente disponível, não existe infraestrutura necessária para que as pessoas tenham acesso a essa água" (UN WATER, 2021). No Brasil, a Constituição Federal aborda a água como um dos elementos do meio ambiente. Nesse sentido, aplica-se à água o enunciado do artigo 225, caput "Todos têm direito ao meio ambiente ecologicamente equilibrado, bem de uso comum do povo". (BRASIL, 1988).

Assim, a Constituição Federal de 1988 categoriza a água como um bem público juridicamente tutelado. "No Estado federado brasileiro, há uma divisão da 
titularidade das águas entre a União e os estados". (AITH; ROTHBARTH, 2015). No artigo 20, inciso III, da referida Carta, é encontrado o seguinte dispositivo: pertencem à União "os lagos, rios e quaisquer correntes de água em terrenos sob seu domínio, ou que banhem mais de um estado, que sirvam de limites com outros países, que provenham ou se estendam a território estrangeiro e também os terrenos marginais e as praias fluviais" (BRASIL, 1988).

A água também é mencionada, de acordo com o Código Civil Brasileiro, em seu livro II, que trata dos "Bens", indica no artigo 99:

I - os de uso comum do povo, tais como rios, mares, estradas, ruas e praças;

II - os de uso especial, tais como edifícios ou terrenos destinados a serviço ou estabelecimento da administração federal, estadual, territorial ou municipal, inclusive os de suas autarquias;

III - os dominicais, que constituem o patrimônio das pessoas jurídicas de direito público, como objeto de direito pessoal, ou real, de cada uma dessas entidades.

Parágrafo único. Não dispondo a lei em contrário, consideram-se dominicais os bens pertencentes às pessoas jurídicas de direito público a que se tenha dado estrutura de direito privado. (BRASIL, 2002)

Nesse sentido, visualiza-se que a água é bem corpóreo, e os rios, mencionados no artigo supracitado são considerados como bens de uso comum do povo. A respeito da conceituação da água sobre um bem comum,

(...) o uso da água não pode ser apropriado por uma só pessoa física ou jurídica, com exclusão absoluta dos outros usuários em potencial; o uso da água não pode significar a poluição ou agressão desse bem; o uso da água não pode esgotar o próprio bem utilizado e a concessão ou a autorização (ou qualquer tipo de outorga) do uso da água deve ser motivada ou fundamentada pelo gestor público. (MACHADO, 2008, p. 443).

Logo, interessante ressaltar a atuação do legislador em considerar todas as águas como "domínio público" no sentido de "bem de uso comum do povo" (MACHADO, 2008). Ainda, de acordo com Paulo Affonso Leme Machado (2008, p. 448), "a água é um recurso natural limitado e não ilimitado, como se raciocinou anteriormente no mundo e no Brasil". Tal afirmativa ressalta o caráter de importância e de proteção que a água deve ter, em razão de todo o cenário de degradação, crescimento populacional e poluição já apresentados. 
Outro diploma jurídico que deve ser mencionado é o Estatuto Jurídico das Águas no Brasil, que tem suas bases na Carta Magna e abrange, de um lado, a proteção dos direitos humanos e, de outro, a proteção do meio ambiente e dos recursos hídricos e naturais refere à proteção dos direitos humanos. A proteção jurídica das águas é uma consequência natural do reconhecimento constitucional de direitos humanos fundamentais, tais como a vida, segurança, dignidade, saúde, alimentação, o consumidor e a cidadania.

Esta preocupação com a água e com o sistema de saneamento básico é essencial, ainda mais quando se está diante de um surto ou de uma pandemia ${ }^{3}$. De acordo com os documentos divulgados pelos órgãos da saúde (UFSM, 2018), o município de Santa Maria, indicado como o município do maior surto de toxoplasmose do mundo, ultrapassando 1.500 casos confirmados na data de 30 de junho de 2018, de acordo com o Centro Estadual de Vigilância em Saúde do Rio Grande de Sul.

Infelizmente, até os dias atuais ainda não se sabe ao certo sobre o maior surto de toxoplasmose do mundo. Segundo o Jornal BBC, a maior parte dos casos de toxoplasmose são isolados. Já os surtos, que acometem um número maior de pessoas em um determinado local e período, são menos comuns. Nesses casos, a causa envolve algum tipo de contaminação ambiental pelo parasita - por exemplo, uma fonte de água, um criadouro de animais, uma área agrícola ou mercado de alimentos. No caso de Santa Maria, ainda não se sabe qual é a origem da contaminação. Identificá-la é justamente a prioridade das autoridades de saúde neste momento. Afinal, como os casos não pararam de aparecer, é possível que a população continue exposta.

De acordo com o município e a Secretária de Saúde e UFSM, cerca de 1.116 caso foram notificados por exames feito pela (Lacen-RS). Infelizmente 35 gestantes, sendo 32 gestantes delas obtiveram a perda do fetos. Os casos confirmados são, na

3 O vírus da Covid-19 poderia sobreviver até nos esgotos? Disponível em: https://saude.abril.com.br/blog/com-a-palavra/o-virus-da-covid-19-poderia-sobreviver-ate-nos-esgotos/ e, também em "Secretário de Saúde de Santa Maria diz que água disseminou surto de toxoplasmose". Disponível em: https://g1.globo.com/rs/rio-grande-do$\mathrm{sul} /$ noticia/2019/03/28/secretario-de-saude-de-santa-maria-diz-que-origem-do-surto-de-toxoplasmosefoi-a-agua.ghtml 
maioria, do sexo feminino (301 pessoas), representando 65,4\%, a faixa etária está entre 20 a 39 anos.

Os bairros santa-marienses com os maiores números de casos são: Tancredo Neves, com 103 pessoas, representando 22,4\%, seguido dos bairros Parque Pinheiro Machado com (com 51 pessoas) e Urlândia (44). Até agora, 1.116 casos foram notificados pelos médicos das redes pública e privada à Superintendência de Vigilância em Saúde desses, 766 são suspeitos, e 350 ainda não foram classificados Entre os casos suspeitos, 460 foram confirmados com toxoplasmose pelo Lacen-RS, (35 são de gestantes), (140 casos foram descartados), (166 ocorrências estão em investigação, sendo 82 de gestantes),A causa da morte de dois fetos (de 28 e 36 semanas) foi confirmada por toxoplasmose, assim como dois abortos (com 14 e 15 semanas de gestação). Um caso de aborto (16 semanas) segue em investigação a causa de um aborto (21 semanas) foi descartada como sendo por toxoplasmose.

A ausência de informação sobre a água no caso do surto de toxoplasmose no município de Santa Maria - RS, mesmo três anos depois, continua.

\section{METODOLOGIA}

Para responder a este problema de pesquisa, utilizou-se do o método indutivo, a fim de nortear a pesquisa documental e doutrinária sobre o direito ao acesso e informação a água. Como método de procedimento foi utilizado o método monográfico. Visto que o presente trabalho tratou em especial de buscar informações em sites, boletins e documentos sobre o caso do surto de toxoplasmose em Santa Maria - RS. As técnicas de pesquisa utilizadas foram as de documentações indiretas pois a pesquisa teve como fonte livros, revistas jurídicas, jurisprudências, artigos científicos e legislação pertinente.

\section{RESULTADOS E DISCUSSÕES}

De acordo com o que foi relatado, no ano de 2021 ainda existem casos ativos de toxoplasmose na cidade de Santa Maria. Restando claro que, sem informação não se pode prevenir contra a toxoplasmose. Sem informação não se pode opinar em processos decisórios.

De acordo com Rossato e Agne Tybusch (2013, p. 716) ao se deparar com a informação e compreender o real significado da questão ambiental, o ser humano é resgatado de sua condição de alienação e passividade. "E, assim, conquista sua 
cidadania, tornando-se apto para envolver-se ativamente na condução de processos decisórios que hão de decidir o futuro da humanidade sobre a Terra" (MILARÉ, 2004, p.342-343). Assim, a informação possibilita com que o indivíduo atue, tome posição e se pronuncie e se previna sobre a matéria em tela.

\section{CONCLUSÃO}

Este trabalho teve o intuito de responder ao seguinte questionamento: Quais os limites e possibilidades para assegurar o direito à água na cidade de Santa Maria/RS frente a ausência de informação sobre o surto de toxoplasmose, nos anos 2017-2018 em Santa Maria - RS? Quais as consequências da doença em gestantes e fetos contaminados neste período? O encontro em 2015 já alertava o mundo sobre seu impacto "Organização Mundial nas Nações Unidas publicou previsões em seu último Relatório das Nações Unidas sobre o Desenvolvimento da Água 2015, sendo uma delas a de que "até 2030, o planeta enfrentará um déficit de água de $40 \%$, a menos que seja melhorada dramaticamente a gestão desse recurso".

No segundo item, foram tratados aspectos relacionados a ausência de informação sobre o surto de toxoplasmose em Santa Maria nos anos de 2017-2018. Três anos após os mais de 1.947 notificações da doença, as informações levantadas por esta pesquisa indicam que podem haver muitas subnotificações diante do pequeno número visualizado em 2021.

A toxoplasmose, é uma doença indicada pela Organização Mundial da Saúde como negligenciada, ou seja, faltam estudos tanto a nível local quanto a nível global sobre a sua incidência e prevalência. Estudos indicam que muitos brasileiros podem ter tido contato com esta doença, cerca de $80 \%$ da população.

Estratégias que envolvam a promoção da educação, principalmente de uma informação qualificada que evite atitudes equivocadas e, principalmente a prevenção devem ser citadas. Assim como, por parte do Poder Público, deveriam existir Redes de Vigilância permanente, com o fim de monitorar, contribuindo assim, não só para a prevenção de doenças como a toxoplasmose, mas de outras que possuem uma transmissibilidade muito grande, tais como a dengue, febre amarela, e agora, a Covid-19, por exemplo. 


\section{AGRADECIMENTOS}

Agradeço a Coordenação do Curso de Direito por todo o incentivo ao longo da minha trajetória na graduação. E, também a Professora Francielle por todo o apoio, carinho e dedicação na orientação deste trabalho.

\section{REFERÊNCIAS}

AGÊNCIA DO SENADO. PEC que torna acesso à água potável direito fundamental vai à Câmara. Disponível em: https://www12.senado.leg.br/noticias/materias/2021/03/31/pec-que-torna-acesso-aagua-potavel-direito-fundamental-vai-a-camara Acesso em: 20 abr. 2020.

AGNE TYBUSCH, Francielle Benini. Biodiversidade, Tecnologia e Sociedade: O Direito à informação ambiental sustentável como possibilidade emancipatória na proteção dos conhecimentos tradicionais. Dissertação - Universidade Federal de Santa Maria, 2016.

AGNE TYBUSCH, Francielle Benini; IRIGARAY, Michele Capuano. A contribuição dos portais brasileiros para a sociedade informacional no processo de informação ambiental sobre a água. Revista de Direito e Sustentabilidade, v. 2, n. 1, p. 59-75, Jan/Jun, 2016. Disponível em: Acesso em: 20 abr. 2020.

AGNE TYBUSCH, Francielle Benini; ROSSATO, Ricardo. Informação Ambiental e Novas Tecnologias: Da Necessidade de Politização para a Sustentabilidade. Revista Eletrônica do Curso de Direito da UFSM. v. 8 (2013).

ARANGUIZ, Dandara Flores. 3 ANOS depois, o que aprendemos com o maior surto de toxoplasmose do mundo? Diário de Santa Maria, Aranguiz, Dandara Flores. Disponível em: https://diariosm.com.br/not\%C3\%ADcias/sa\%C3\%BAde/3anos-depois-o-que-aprendemos-com-o-maior-surto-de-toxoplasmose-do-mundo1.2323456 Acesso em: 22 abr. 2021 a.

ARANGUIZ, Dandara Flores. Para infectologista, estudo ajudaria a entender realidade atual da toxoplasmose aqui. Diário de Santa Maria, Aranguiz, Dandara Flores. Disponível em: https://diariosm.com.br/not\%C3\%ADcias/sa\%C3\%BAde/parainfectologista-estudo-ajudaria-a-entender-realidade-atual-da-toxoplasmose-aqui1.2323481 Acesso em: 22 abr. 2021 b. 
BARLOW, Clake; MAURE, Tony. Ouro Azul. São Paulo: M, Books do Brasil Ltda, 2003.

BBC. O que é a toxoplasmose, doença que traz riscos à gravidez e você pode ter tido BBC. O que é a toxoplasmose, doença que traz riscos à gravidez e você pode ter tido sem saber. Disponível em: https://www.bbc.com/portuguese/brasil43832988 Acesso em: 18 denov. de 2019.sem saber. Disponível em: https://www.bbc.com/portuguese/brasil-43832988 Acesso em: 18 nov. 2019.

BRASIL. Constituição da República Federativa do Brasil de 1988. Brasília, DF: Presidência da República, [2016]. Disponível em: http://www.planalto.gov.br/ccivil_03/Constituicao/ Constituiçao.htm. Acesso em: 16 mar.2021.

CORSAN.Resolução CSR 01/2020, emitida pela Agesan. Publicada no Diário Oficial dos Municípios do Estado do Rio Grande do Sul em 10/01/2020. Edição 2725. REGULAMENTO DOS SERVIÇOS DEÁGUA E ESGOTO, [2020]. Disponível em: https://www.corsan.com.br/upload/arquivos/202006/16111059-regulamento-dosservicos-de-agua-e-esgoto-agesan.pdf Acesso em:16 mar.2021.

DALMONTE, L. C. Enfrentamento do surto de toxoplasmose em Santa Maria/RS no ano de 2018. Revista Multidisciplinar Em Saúde, 2(1), 12, 2021. Disponível em: https://doi.org/10.51161/rems/691 Acesso em:16 mar. 2021.

DECLARAÇÃo Universal dos Direitos da Água. Disponívelem:<http://www.ambientebrasil.com.br/composer.php3?base=./agua/doce/ index.html\&conteudo=./agua/declaracaoag ua.html>. Acesso em: 15 mar. 2021.

ESTADO DO RIO GRANDE DO SUL. Nota informativa. Assunto: Surto de Toxoplasmose em Santa Maria-RS. Disponível em: https://www.santamaria.rs.gov.br/docs/noticia/2018/04/D19-1396.pdf Acesso em: 15 mar. 2021.

MACHADO, Paulo Affonso Leme. Direito Ambiental Brasileiro. Malheiros Editores, 2007.

MILARÉ, Édis. Direito do ambiente. 3a edição. São Paulo: Revista dos Tribunais, 2004.

NAÇÕES UNIDAS. Água potável: direito humano fundamental. Disponível em: https://nacoesunidas.org/agua-potavel-direito-humano-fundamental/ Acesso em: 10 nov. 2019.

O DIREITO Humano à Água e ao Saneamento Abril 2011. Disponível em: https://www.un.org/waterforlifedecade/pdf/human_right_to_water_and_sanitation_mil estones_por.pdf Acesso em: 27 mar. 2020. 
PES, João Hélio Ferreira Pes. Água potável: Direito fundamental de acesso, dever fundamental de fornecimento. Rio de Janeiro: Editora Lumen Juris, 2019.

PES, João Hélio Ferreira Pes; ROSA, Taís Hemann. O direito fundamental de acesso à água e a interrupção do serviço público de abastecimento. Anais do [Recurso eletrônico] XXI Encontro Nacional do CONPEDI. Florianópolis: Fundação Boiteux, 2012. Disponível em: http://www.publicadireito.com.br/artigos/?cod=82cadb0649a3af49 Acesso em: 23 abr. 2021.

PES, João Hélio Ferreira Pes. Direito fundamental de acesso à água e o mínimo existencial ambiental. Revista de Direito da Cidade. Vol. 11, no 4. Disponível em: https://www.e-publicacoes.uerj.br/index.php/rdc/article/view/40604 Acesso em: 23 abr. 2021.

SURTO de toxoplasmose em Santa Maria é o maior no mundo: Diário de Santa Maria, 28/05/2018, Geral, Online. Local: UFSM-RS, autora :Ceretta Thays Publicador, 28, maio ,2018 de publicação. Disponível em: URL. http://coral.ufsm.br/midia/?p=43645 Acesso em: 15 maio 2021.

UFSM. Surto de toxoplasmose em Santa Maria é o maior no mundo. Disponível em: http://coral.ufsm.br/midia/?p=43645 Acesso em: 10 de nov. 2020. 